\title{
Unsur Hijau pada Ruang Publik dan Sisa Halaman Rumah Kampung Cibunut RW 07 RT 05 Kota Bandung
}

\author{
Irfan Sabarilah Hasim \\ Program Studi Arsitektur, Fakultas Arsitektur dan Desain, \\ Institut Teknologi Nasional Bandung \\ Email: ishasim@itenas.ac.id
}

\begin{abstract}
ABSTRAK
Tanaman sangat penting untuk menunjang kehidupan sebagai penunjang kesehatan, pengendali iklim mikro, menyerap polusi bahkan berguna meningkatkan kualitas visual. Kehadiran tanaman di lingkungan perkotaan semakin sulit, mengingat lahan-lahan perkotaan semakin sempit terutama di lingkungan permukiman kota yang umumnya padat dan menyisakan sedikit ruang untuk tanaman. Berbeda dengan permukiman-permukiman padat pada umumnya, Kampung Cibunut RW 07 khususnya RT 05 Kota Bandung terlihat lebih asri, banyak sekali tanaman di lingkungan ini, meskipun lahan terbuka sedikit, gang juga tidak terlalu besar dan teras-teras rumah sangat terbatas. Melihat perkembangan yang sangat baik di Kampung Cibunut, maka penelitian ini layak untuk dilakukan dengan tujuan untuk mengidentifikasi jumlah dan jenis tanaman, serta cara dan metoda penanaman di ruang sempit dan mengetahui luas diameter tajuk tanaman. Digunakan metoda deskriptif kualitatif, data dikumpulkan melalui survey dan studi pustaka. Data primer diperoleh melalui observasi lapangan, pengukuran dan pencatatan langsung di lapangan. Setiap tanaman diberi nomor, dan dicatat kemudian seluruh data akan dimasukan ke dalam matrik untuk memudahkan perhitungan. Pembahasan dilakukan untuk mendapatkan ragam jenis tanaman, sistem dan cara penanaman, dan luas total tajuk tanaman. Diharapkan hasil dari penelitian ini dapat ditiru dan diterapkan di permukiman padat sejenis di kota Bandung agar dapat meningkatkan keasrian kawasan dan penyerapan polusi.
\end{abstract}

Kata kunci : Tanaman, Unsur Hijau, Lahan sempit, permukiman padat.

\begin{abstract}
Plants are very important to support life as health support, control the microclimate, absorb pollution, and even improve visual quality. The presence of plants in urban environments is increasingly difficult, given that urban lands are increasingly narrow, especially in urban residential areas which are generally dense and leave little room for plants. Unlike the dense settlements in general, Kampung Cibunut RW 07, especially RT 05 Kota Bandung, looks more beautiful, there are lots of plants in this environment, although there is little open land, the alleys are not too big and the terraces of the houses are very limited. Seeing the excellent development in Cibunut Village, this research is feasible to do the aim of identifying the number and types of plants, as well as methods and methods of planting in narrow spaces and knowing the diameter of the plant canopy. Qualitative descriptive method is used, data is collected through surveys and literature studies. Primary data obtained through field observations, measurements, and direct notes in the field. Each plant is numbered, recorded and then all data will be entered into a matrix to facilitate calculation. Discussions were conducted to obtain various types of plants, planting systems and methods, and the total area of the plant canopy. It is hoped that the results of this research can be replicated and applied in similar dense settlements in the city of Bandung to increase the beauty of the area and the absorption of pollution.
\end{abstract}

Keywords: Plants, Green Element, Narrow land, dense settlement. 


\section{PENDAHULUAN}

Sejak jaman dahulu unsur vegetasi atau taman, adalah unsur yang mewah, bukan sesuatu yang menjadi prioritas utama. Seringkali hadir kalau ada ruang sisa yang tidak dipergunakan lagi. Padahal keberadaan tanaman sangat penting untuk menunjang kehidupan. Slamet dalam A. Saraswati (2008) menyatakan bahwa ada sembilan fungsi dan peranan penghijauan perkotaan yang menjelaskan pentingnya keberadaan RTH [1] yaitu: (1) sebagai paru-paru kota; (2) sebagai pengatur lingkungan (mikro), vegetasi akan menimbulkan hawa lingkungan setempat sejuk, nyaman dan segar; (3) pencipta lingkungan hidup (ekologis); (4) penyetimbangan alam (adaphis) merupakan pembentukan tempattempat hidup alam bagi satwa yang hidup di sekitarnya; (5) perlindungan (protektif) terhadap kondisi fisik alami sekitarnya (angin kencang, terik matahari, gas atau debu-debu); (6) keindahan (estetika); (7) kesehatan (hygiene), misalnya untuk terapi mata; (8) rekreasi dan pendidikan (edukatif) (9) Sosial politik ekonomi.

Mengingat pentingnya tanaman untuk menunjang kehidupan, maka cara paling baik adalah menanam sebanyak yang kita bisa dimanapun, di ruang seluas atau sekecil apapun. Kalau kita tidak mampu menanam tanaman besar karena ruang yang sempit, maka tanamlah tanaman yang kecil, atau tanaman hias sebanyak yang kita bisa. Karena tanaman hias, meskipun kecil, manfaatnya banyak. Carpenter dalam Riddati (2014) menyatakan bahwa tanaman bisa berfungsi sebagai kontrol pandangan (visual control), pembatas fisik (physical barriers), pengendali iklim (climate control), pencegah erosi (erosion control), habitat binatang (wildlife habitat) dan nilai estetis (aesthetic values) [2].

Keberadaan unsur hijau di perkotaan, terutama di permukiman padat lebih mengkhawatirkan lagi. Karakteristik yang bisa kita lihat langsung adalah padatnya permukiman, dan menyisakan sedikit sekali ruang terbuka (open space). Banyak rumah-rumah sudah tidak mempunyai halaman lagi. Kalaupun ada yang menyisakan teras, jumlahnya tidak banyak dan tidak begitu luas. Disamping itu pada umumnya masyarakat permukiman padat lebih mementingkan kebutuhan akan ruang untuk tempat tinggal dibanding untuk kebutuhan lain seperti taman atau ruang untuk tanaman. Banyak sekali permukiman padat di kota yang berawal dan berkembang dari kampung tradisional, rumah-rumah panggung menjadi sebuah kampung atau perkampungan yang berada di Kota. Menurut Setiawan dalam Nursyahbani (2015) dapat dijelaskan sebagai sebuah perumahan atau pemukiman yang seperti kampung di pedesaan, tapi berada di perkotaan umum disebut sebagai Kampung Kota [3]. Sementara kalau kita lihat definisi kampung menurut KBBI adalah[4] :

1. kelompok rumah yang merupakan bagian kota (biasanya dihuni orang berpenghasilan rendah)

2. n desa; dusun

3. $\mathrm{n}$ kesatuan administrasi terkecil yang menempati wilayah tertentu, terletak di bawah kecamatan

4. a terbelakang (belum modern); berkaitan dengan kebiasaan di kampung; kolot

Jadi bisa dikatakan bahwa permukiman atau perkampungan padat di kota adalah kelompok rumah yang dihuni orang berpenghasilan rendah, belum modern yang berada di perkotaan. Karakter permukiman umumnya padat, jalan atau gang sempit, sisa halaman rumah sudah sangat sedikit.
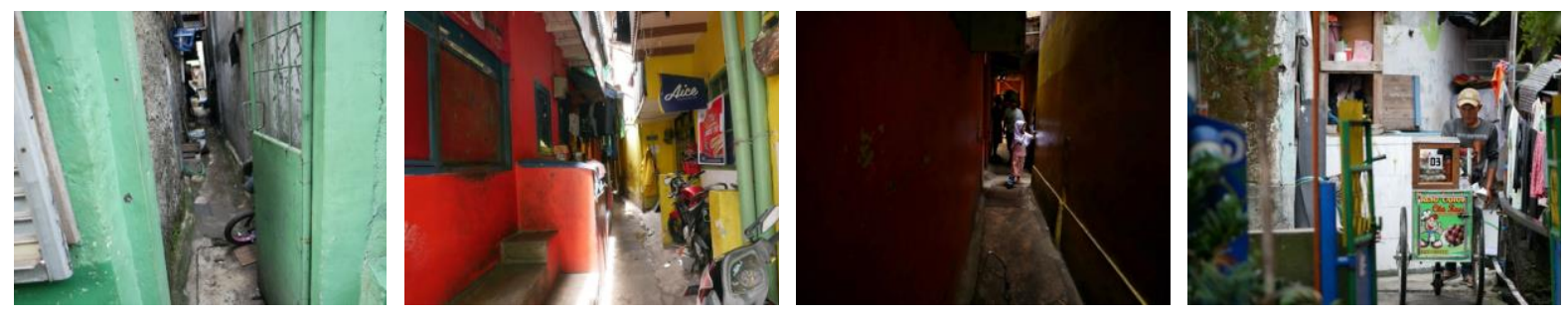

Gambar 1. Karakter ruang yang sempit di permukiman padat kota

Jurnal Arsitektur Terracotta- 152 
Di Indonesia seharusnya ruang publik itu indah dilengkapi oleh tanaman. Sesuai dengan apa yang dipaparkan oleh Badan Penelitian dan Pengembangan Kehutanan dalam pengantar buku terjemahan karya Heyne (1987) dikatakan bahwa dibanding banyak negara lain di dunia ini, sesungguhnya Tuhan yang Maha Pemurah telah memanjakan Bangsa Indonesia dalam pemberian kekayaan flora [5]. Bahkan di dalam terjemahan buku karya Heyne yang berjumlah 4 buku di uraikan tidak kurang dari 3.500 jenis tumbuhan yang berguna di Indonesia. Sebagai contoh, sebuah penelitian yang dilakukan di Desa Cimenteng dan penelusuran pustaka, diidentifikasi 48 jenis tumbuhan potensi obat [6]. Tanaman selain berguna untuk kesehatan, obat-obatan atau pengendali iklim mikro, juga berguna sebagai unsur estetis atau keindahan. Menurut Eckbo dalam Subadyo dalam Purwanti (2010), kualitas estetika lanskap merupakan salah satu faktor yang secara langsung dapat memberikan kepuasan kepada pengguna. Kualitas estetika lanskap walaupun sulit untuk dinyatakan secara obyektif namun dapat diukur melalui reaksi dari respon manusia [7]. Fungsi tanaman yang lain adalah kemampuannya dalam menyerap bau busuk atau polusi udara. Rahmawati dalam Syamsia (2015) menyatakan, Jika hidung dapat mencium bau pencemar udara atau bahkan merasa sesak pada dada akibat mencium gas tersebut, hal ini berarti tingkat pencemaran udara sudah tinggi dan mungkin saja akan menjadi racun yang dapat mematikan [8]. Fungsi tanaman dalam menyerap bau busuk sangat penting. Polutan akan diserap dan diteruskan ke akar, untuk kemudian diurai menjadi zat yang sudah tidak berbahaya lagi.

Ruang publik memegang peranan penting, terutama kalau kita melihat karakter masyarakat Indonesia yang pada umumnya senang bersosialisasi. Ruang publik mempunyai manfaat yang sangat banyak, menurut Darmawan dalam A. Pratomo (2019) ruang publik adalah elemen perkotaan yang memiliki karakter tersendiri dan memiliki fungsi interaksi sosial bagi masyarakat, kegiatan ekonomi dan apresiasi budaya [9]. Bahkan kalau kita melihat karakter kampung di Indonesia, khususnya Jawa Barat, interaksi sosial hampir tiap hari terjadi di ruang publik, baik itu ruang terbuka yang besar atau bahkan di ganggang yang sempit. Oleh karena itu sekecil apapun ruang publik, selain memberikan ruang kepada masyarakat, juga harus mampu memberikan makna kepada penghuni, seperti yang disebut Carr dalam Trimurti (2019) bahwa ruang terbuka publik harus responsif, demokratis dan bermakna [10].

Roger Trancik dalam Zahnd dalam Olinda Rodrigues (2019) mengemukakan bahwa sebuah space akan berubah menjadi sebuah place jika memiliki karakteristik dan makna tertentu yang kontekstual bagi lingkunganya. Sementara menurut Carmona dalam Olinda Rodrigues (2019) suatu tempat (place) yang mempunyai nilai/ makna yang besar mempunyai tiga unsur; yaitu aktifitas, bentuk dan imej [11]. Karakteristik dan makna dapat diciptakan dari unsur-unsur visual, misalnya bentuk, tekstur maupun warna. Berkaitan dengan makna sebuah tempat Kampung Cibunut sudah memilikinya. Selain aktifitas masyarakatnya yang hidup, Kampug Cibunut sudah mempunyai imej, kampung yang bersih, asri dan penuh warna.

\subsection{Tujuan Penelitian}

Berbeda dengan permukiman-permukiman padat pada umumnya, Kampung Cibunut RW 07 Kota Bandung ini terlihat lebih asri, meskipun lahan terbuka sedikit, gang juga tidak terlalu besar dan terasteras rumah sangat terbatas. Sekilas dapat dilihat bahwa kampung ini tampil dengan penuh warna dan sangat segar.
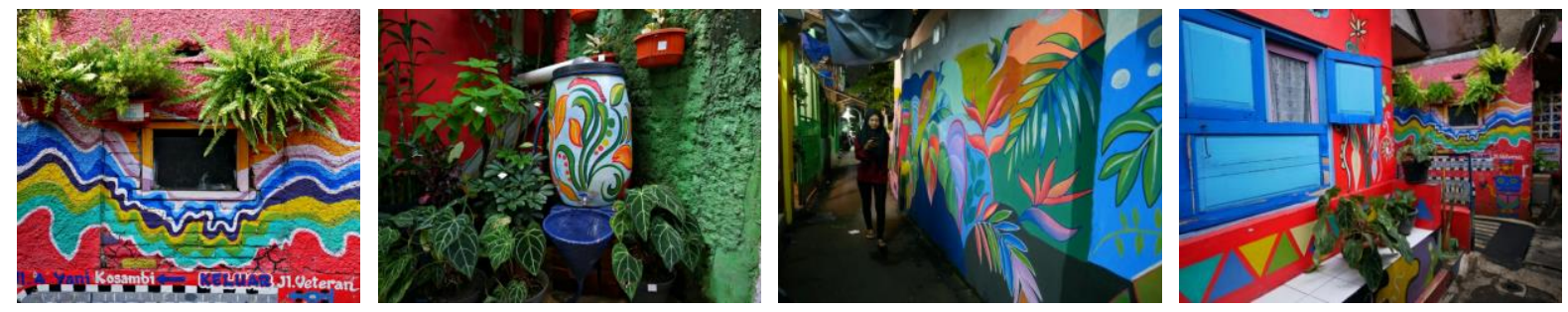

Gambar 2. Karakter ruang Kampung Cibunut Kota Bandung yang asri dan penuh warna 
Kampung ini meriah oleh warna bangunan yang dicat dan diberi gambar-gambar yang menarik dan dilengkapi dengan tanaman-tanaman hias. Khusus di RT 05 tanaman-tanaman yang menghiasi sisa halaman, dinding rumah, jalan dan gang sangat banyak, sehingga menampilkan pemandangan yang sangat asri dan menyegarkan. Melihat perkembangan yang sangat baik terjadi di Kampung Cibunut, maka penelitian ini layak untuk dilakukan, supaya sesuatu yang baik bisa dicontoh untuk mengembangkan kampung yang serupa. Adapun rumusan permasalahan yang akan dijadikan dasar penelitian yaitu :

1. Berapa banyak jumlah dan jenis spesies tanaman di Kampung Cibunut?

2. Bagaimana cara dan metoda penanaman di sisa lahan Kampung Cibunut ?

3. Berapa luas total diameter tajuk hijau tanaman di kawasan Kampung Cibunut RT 05 apabila dijumlahkan?

Penelitian ini bertujuan untuk :

1. Mengetahui dan mengidentifikasi jumlah dan jenis tanaman di Kampung Cibunut.

2. Mengidentifikasi sistem, cara dan metoda penanaman di ruang Kampung Cibunut.

3. Mengetahui luas total diameter tajuk tanaman di Kawasan Kampung Cibunut Kota.

\section{METODOLOGI}

\subsection{Lokasi dan waktu penelitian}

Penelitian dilaksanakan di Kampung Cibunut RW 07 Kelurahan Kebun Pisang Kecamatan Sumur Bandung Kota Bandung Jawa Barat dengan fokus penelitan di RT 05. Waktu penelitian lapangan dilakukan selama 3 (tiga) bulan.

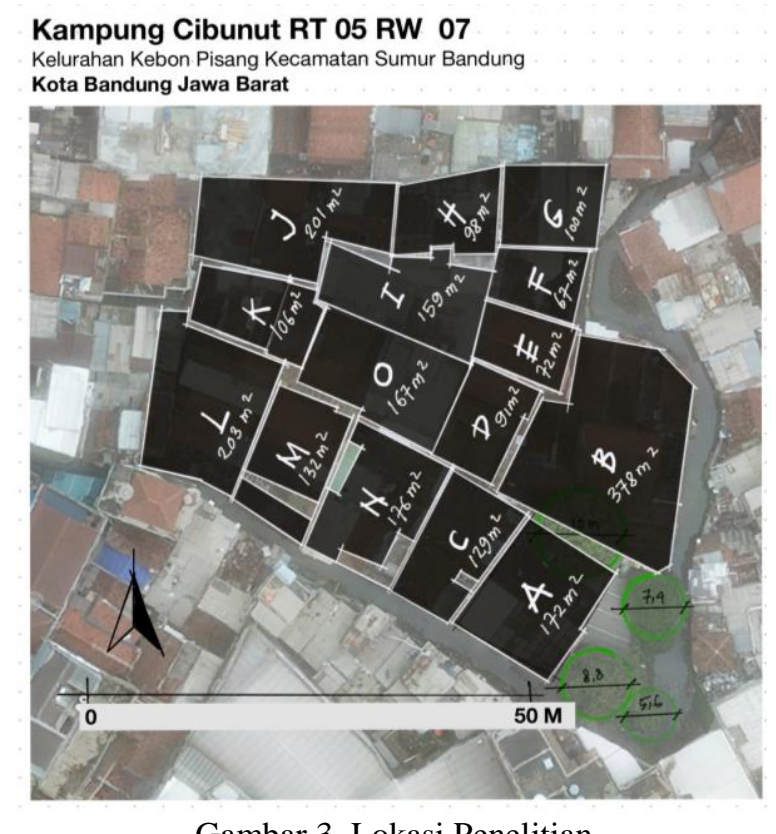

Gambar 3. Lokasi Penelitian

Metode pengumpulan data diperoleh dari data primer dan data sekunder. Data primer yang diperoleh melalui observasi lapangan, pengukuran dan pencatatan langsung yang meliputi: jenis dan jumlah tanaman, cara peletakan tanaman dan diameter tajuk. Setiap tanaman akan diberi kode rumah A sampai dengan $\mathrm{O}$ (gambar 4) dan penomoran, kemudian dimasukan ke dalam matriks untuk memudahkan pencatatan dan pembahasan. 

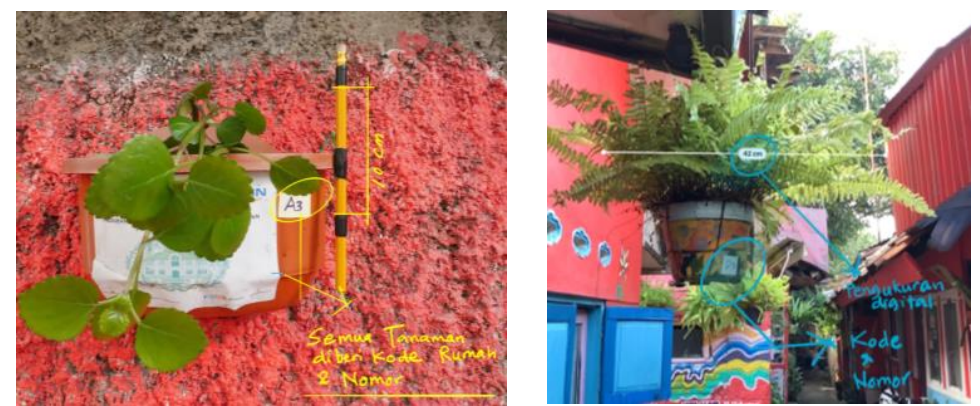

Gambar 4. Cara pengukuran dan pencatatan

Tabel 1. Sample Pengisian Data

\begin{tabular}{lllllll}
\hline Kode & Jenis Tanaman & Cara Peletakan & $\begin{array}{l}\text { Material Media Tanam/ } \\
\text { Pot }\end{array}$ & $\begin{array}{l}\text { Tinggi Pot } \\
\text { (cm) }\end{array}$ & $\begin{array}{l}\text { Diameter } \\
\text { pot }\end{array}$ & $\begin{array}{l}\text { Diameter } \\
\text { Tajuk (cm) }\end{array}$ \\
\hline A1 & Pakis Boston & Pot di dinding & Pot Plastik & 10 & 20 & 45 \\
\hline A2 & Bromelia & Pot di atas tanah & Pot Plastik & 12 & 15 & 45 \\
\hline A3 & Episcia & Pot di dinding & Pot Plastik & 10 & 20 & 10 \\
\hline A4 & Pakis Boston & Pot di dinding & Pot Plastik & 10 & 20 & 45 \\
\hline A5 & Keladi Hijau & Pot di dinding & Pot Plastik & 10 & 20 & 50 \\
\hline A6 & Spider Lily & Pot di dinding & Pot Plastik & 10 & 20 & 45 \\
\hline A7 & Episcia & Pot di dinding & Pot Plastik & 10 & 20 & 35 \\
\hline A8 & Pakis Boston & Pot di dinding & Pot Plastik & 10 & 20 & 40 \\
\hline A9 & Keladi Hijau & Pot di dinding & Pot Plastik & 10 & 20 & 50 \\
\hline A10 & Spider Lily & Pot di atas tanah & Bekas Botol Kemasan & 10 & 5 & 15 \\
\hline
\end{tabular}

\section{HASIL DAN PEMBAHASAN}

\subsection{Jumlah dan jenis Tanaman}

Total jumlah tanaman yang berhasil diidentifikasi berjumlah 387 tanaman dengan total jenis 50 tanaman. Tiga tanaman yang paling banyak ditanam adalah sebagai berikut: (1) Spider plant sebanyak 45 buah, (2) Pakis boston 34 buah dan (3) Keladi hijau 32 buah (lihat Tabel 1)

Tabel 2. Total Jenis dan Jumlah Tanaman Kampung Cibunut RW 07 RT 05

\begin{tabular}{lllllllll}
\hline No & Nama Tanaman & Jml & No & Nama Tanaman & Jml & No & Nama Tanaman & Jml \\
\hline 1 & Spider plant & 45 & $\mathbf{1 8}$ & Iresine & 6 & $\mathbf{3 5}$ & Lidah Buaya & 2 \\
\hline 2 & Pakis Boston & 34 & $\mathbf{1 9}$ & peach lily & 6 & $\mathbf{3 6}$ & mangga (kecil) & 2 \\
\hline 3 & Keladi hijau & 32 & $\mathbf{2 0}$ & pucuk merah & 6 & $\mathbf{3 7}$ & Miana coleus Ungu & 2 \\
\hline 4 & Dieffenbachia & 24 & $\mathbf{2 1}$ & Cemara embun & 5 & $\mathbf{3 8}$ & Miana Kuning & 2 \\
\hline $\mathbf{5}$ & Anthurium & 18 & $\mathbf{2 2}$ & Hanjuang & 5 & $\mathbf{3 9}$ & soka & 2 \\
\hline $\mathbf{6}$ & Peperomia clusiifolia & 16 & $\mathbf{2 3}$ & Miana & 5 & $\mathbf{4 0}$ & Ararea & 1 \\
\hline $\mathbf{7}$ & Episcia & 15 & $\mathbf{2 4}$ & Zamioculcas & 5 & $\mathbf{4 1}$ & Bambu air & 1 \\
\hline $\mathbf{8}$ & Agloenema & 14 & $\mathbf{2 5}$ & begonia & 4 & $\mathbf{4 2}$ & Jeruk & 1 \\
\hline $\mathbf{9}$ & kuping gajah & 13 & $\mathbf{2 6}$ & Paku Sarang Burung & 4 & $\mathbf{4 3}$ & kastuba & 1 \\
\hline
\end{tabular}




\begin{tabular}{lllllllll}
\hline No & Nama Tanaman & Jml & No & Nama Tanaman & Jml & No & Nama Tanaman & Jml \\
\hline $\mathbf{1 0}$ & Sirih gading & 13 & $\mathbf{2 7}$ & Puring & 4 & $\mathbf{4 4}$ & Mangga (besar) & 1 \\
\hline $\mathbf{1 1}$ & walisongo & 12 & $\mathbf{2 8}$ & euphorbia & 3 & $\mathbf{4 5}$ & marantha bali & 1 \\
\hline $\mathbf{1 2}$ & Dracaena & 12 & $\mathbf{2 9}$ & klengkeng & 3 & $\mathbf{4 6}$ & Monstera & 1 \\
\hline $\mathbf{1 3}$ & Dracaena surculosa & 11 & $\mathbf{3 0}$ & pacar cina & 3 & $\mathbf{4 7}$ & Paku Tanduk Rusa & 1 \\
\hline $\mathbf{1 4}$ & Anggrek & 10 & $\mathbf{3 1}$ & pandan & 3 & $\mathbf{4 8}$ & Palm & 1 \\
\hline $\mathbf{1 5}$ & Sansevieria & 8 & $\mathbf{3 2}$ & bromeliad & 2 & $\mathbf{4 9}$ & pepaya (kecil) & 1 \\
\hline $\mathbf{1 6}$ & proiphys amboinensis & 7 & $\mathbf{3 3}$ & Gelombang Cinta & 2 & $\mathbf{5 0}$ & Sirih Hijau & 1 \\
\hline $\mathbf{1 7}$ & balsam & 6 & $\mathbf{3 4}$ & Kamboja jepang & 2 & & tidak teridentifikasi & 8 \\
\hline & & & & & TOTAL & $\mathbf{3 8 7}$ \\
\hline
\end{tabular}

\subsection{Cara Peletakan}

Berdasarkan pengamatan dan penghitungan lapangan, tercatat 387 tanaman dengan cara penanaman/ peletakan tanaman sebagai berikut: (1) Tanaman diletakan dalam pot di atas tanah berjumlah 251 , (2) Tanaman di tempel di dinding berjumlah 72, (3) Tanaman digantung berjumlah 28, (4) Tanaman diletakan di pagar, dijepit, digantung atau ditempel berjumlah 22 (5) Tanaman di tanam langsung di tanah berjumlah 14 .

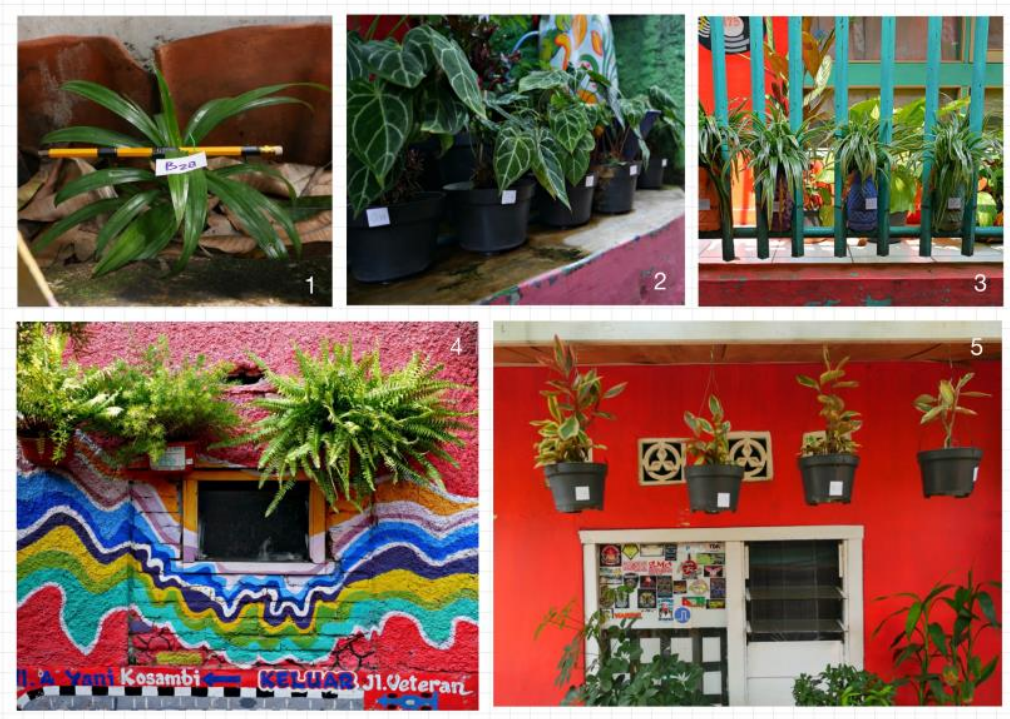

Gambar 6. Cara Peletakan Tanaman

\subsection{Luas Tajuk Tanaman}

Untuk mendapatkan perhitungan total luas tajuk tanaman, maka setiap tanaman diberi Kode rumah dari A sampai dengan $\mathrm{O}$ (total 15 rumah), masing-masing kode diurut dengan nomor dari 1 sampai angka terakhir di setiap rumah. Didalam pengamatan ada dua rumah yang sama sekali tidak mempunyai tanaman yaitu dengan kode $\mathrm{F}$ dan $\mathrm{H}$, karena gang nya sangat sempit dan gelap. Berikut adalah tabel-tabel pencatatan dan penghitungan tanaman setiap rumah.

Tabel 3. Luas Total Tajuk Tanaman Rumah A (satuan meter)

\begin{tabular}{lllllllll}
\hline & Jenis & $\begin{array}{l}\text { Luas } \\
\text { Tajuk/m2 }\end{array}$ & & Jenis & $\begin{array}{l}\text { Luas } \\
\text { Tajuk/m2 }\end{array}$ & Jenis & $\begin{array}{l}\text { Luas } \\
\text { Tajuk/m2 }\end{array}$ \\
\hline A1 & Pakis Boston & 0,16 & A25 & Aglaonema & 0,07 & A49 & Pakis Boston & 0,13 \\
\hline A2 & Bromelia & 0,16 & A26 & Peach lily & 0,20 & A50 & soka & 0,03 \\
\hline
\end{tabular}


Unsur Hijau pada Ruang Publik dan Sisa Halaman Rumah Kampung Cibunut RW 07 RT 05 Kota Bandung

\begin{tabular}{|c|c|c|c|c|c|c|c|c|}
\hline & Jenis & $\begin{array}{l}\text { Luas } \\
\text { Tajuk/m2 }\end{array}$ & & Jenis & $\begin{array}{l}\text { Luas } \\
\text { Tajuk/m2 }\end{array}$ & & Jenis & $\begin{array}{l}\text { Luas } \\
\text { Tajuk/m2 }\end{array}$ \\
\hline A3 & Episcia & 0,01 & A27 & Begonia & 0,07 & A51 & Anggrek & 0,00 \\
\hline A4 & Pakis Boston & 0,16 & A28 & Aglaonema & 0,20 & A52 & - & 0,07 \\
\hline A5 & Keladi Hijau & 0,20 & A29 & Pakis Boston & 0,13 & A53 & Anggrek & 0,07 \\
\hline A6 & Spider Plant & 0,16 & A30 & Walisongo & 0,13 & A54 & Pakis Boston & 0,10 \\
\hline A7 & Episcia & 0,10 & A31 & Kuping Gajah & 0,05 & A55 & Spider Plant & 0,02 \\
\hline A8 & Pakis Boston & 0,13 & A32 & Dieffenbachia & 0,13 & A56 & mati & 0,00 \\
\hline A9 & Keladi Hijau & 0,20 & $\mathbf{A 3 3}$ & Dracaena J. & 0,07 & A57 & Keladi hijau & 0,07 \\
\hline A10 & Spider Plant & 0,02 & A34 & Dieffenbachia & 0,07 & A58 & Puring & 0,02 \\
\hline A11 & Iresine & 0,01 & A35 & Dieffenbachia & 0,10 & A59 & Keladi hijau & 0,03 \\
\hline A12 & Dieffenbachia & 0,01 & A36 & - & 0,01 & A60 & Pakis Boston & 0,20 \\
\hline A13 & Iresine & 0,05 & A37 & Iresine & 0,03 & A61 & Paku S. Burung & 0,28 \\
\hline A14 & Spider Plant & 0,05 & A38 & Dieffenbachia & 0,07 & A62 & Pakis Boston & 0,20 \\
\hline A15 & Spider Plant & 0,13 & A39 & Keladi hijau & 0,07 & A63 & Pakis Boston & 0,28 \\
\hline A16 & Spider Plant & 0,05 & A40 & soka & 0,03 & A64 & Sansevieria & 0,03 \\
\hline A17 & Spider Plant & 0,02 & A41 & Pakis Boston & 0,01 & A65 & Dracaena & 0,07 \\
\hline A18 & Dracaena s. & 0,05 & A42 & Pakis Boston & 0,10 & A66 & Dracaena s. & 0,01 \\
\hline A19 & Spider Plant & 0,02 & A43 & Anggrek & 0,07 & A67 & Aglaonema & 0,07 \\
\hline A20 & Sirih gading & 0,00 & A44 & Keladi hijau & 0,00 & A68 & Dracaena & 0,02 \\
\hline A21 & Episcia & 0,03 & A45 & Anggrek & 0,05 & A69 & Aglaonema & 0,28 \\
\hline $\mathbf{A 2 2}$ & Dieffenbachia & 0,28 & A46 & Aglaonema & 0,03 & A70 & Episcia & 0,01 \\
\hline $\mathbf{A 2 3}$ & Begonia & 0,16 & A47 & tak terdefinisi & 0,07 & A71 & Pakis Boston & 0,03 \\
\hline \multirow[t]{2}{*}{ A24 } & Dieffenbachia & 0,07 & A48 & Pakis Boston & 0,16 & & & \\
\hline & & & & & & & TOTAL & 6,11 \\
\hline
\end{tabular}

Tabel 4. Luas Total Tajuk Tanaman Rumah B

\begin{tabular}{lllllllll}
\hline & Jenis & $\begin{array}{l}\text { Luas } \\
\text { Tajuk/m2 }\end{array}$ & & Jenis & $\begin{array}{l}\text { Luas } \\
\text { Tajuk/m2 }\end{array}$ & & Jenis & $\begin{array}{l}\text { Luas } \\
\text { Tajuk/m2 }\end{array}$ \\
\hline B1 & Lidah Buaya & 0,16 & $\mathbf{B 2 9}$ & Hanjuang & 0,20 & B58 & kosong & 0,00 \\
\hline B2 & Keladi & 0,07 & $\mathbf{B 3 0}$ & Hanjuang & 0,16 & B59 & kosong & 0,00 \\
\hline B3 & Iresine & 0,03 & $\mathbf{B 3 1}$ & Anggrek & 0,02 & B60 & Keladi hijau & 0,05 \\
\hline B4 & Spider Plant & 0,10 & $\mathbf{B 3 2}$ & Sirih Gading & 0,03 & $\mathbf{B 6 1}$ & Keladi hijau & 0,10 \\
\hline B5 & Spider Plant & 0,06 & $\mathbf{B 3 3}$ & Lidah Buaya & 0,07 & $\mathbf{B 6 2}$ & Aglaonema & 0,05 \\
\hline B6 & Spider Plant & 0,03 & $\mathbf{B 3 4}$ & Iresine & 0,02 & $\mathbf{B 6 3}$ & Aglaonema & 0,20 \\
\hline B7 & Keladi & 0,13 & $\mathbf{B 3 5}$ & Jawer Kotok & 0,03 & $\mathbf{B 6 4}$ & Spider Plant & 0,07 \\
\hline B8 & Episcia & 0,03 & $\mathbf{B 3 6}$ & Mangga & 0,02 & $\mathbf{B 6 5}$ & Spider Plant & 0,07 \\
\hline B9 & Spider Plant & 0,09 & $\mathbf{B 3 7}$ & Keladi hijau & 0,03 & $\mathbf{B 6 6}$ & Dracaena & 0,05 \\
\hline B10 & Spider Plant & 0,03 & $\mathbf{B 3 8}$ & Aglaonema & 0,05 & $\mathbf{B 6 7}$ & Spider Plant & 0,07 \\
\hline B11 & Spider Plant & 0,07 & $\mathbf{B 3 9}$ & Sirih Gading & 0,07 & $\mathbf{B 6 8}$ & Episcia & 0,07 \\
\hline B12 & Spider Plant & 0,09 & $\mathbf{B 4 0}$ & Anggrek & 0,01 & $\mathbf{B 6 9}$ & Paku S. Burung & 0,16 \\
\hline & & & & & &
\end{tabular}




\begin{tabular}{|c|c|c|c|c|c|c|c|c|}
\hline & Jenis & $\begin{array}{l}\text { Luas } \\
\text { Tajuk/m2 }\end{array}$ & & Jenis & $\begin{array}{l}\text { Luas } \\
\text { Tajuk/m2 }\end{array}$ & & Jenis & $\begin{array}{l}\text { Luas } \\
\text { Tajuk/m2 }\end{array}$ \\
\hline B13 & Keladi hijau & 0,05 & B41 & Anggrek & 0,01 & B70 & Keladi hijau & 0,10 \\
\hline B14 & Palm & 0,03 & B42 & Anggrek & 0,01 & B71 & Spider Plant & 0,03 \\
\hline B15 & Ararea & 0,07 & B43 & Iresine & 0,02 & B72 & Pakis Boston & 0,07 \\
\hline B16 & Dracaena & 0,03 & B44 & Anggrek & 0,03 & B73 & Pakis Boston & 0,20 \\
\hline B17 & Sansevieria & 0,02 & B46 & klengkeng & 0,20 & B74 & Cemara embun & 0,10 \\
\hline B18 & Aglaonema & 0,05 & B47 & klengkeng & 0,28 & B75 & Pakis Boston & 0,16 \\
\hline B19 & Walisongo & 0,05 & B48 & klengkeng & 0,50 & B76 & Spider Plant & 0,05 \\
\hline B20 & Peach lily & 0,07 & B49 & mangga & 0,03 & B77 & Pakis Boston & 0,07 \\
\hline B21 & Kuping Gajah & 0,13 & B50 & Kuping Gajah & 0,07 & B78 & Pakis Boston & 0,16 \\
\hline B22 & Dracaena s. & 0,20 & B51 & pepaya (kecil) & 0,03 & B79 & Keladi hijau & 0,16 \\
\hline B23 & Sirih Gading & 0,07 & B52 & pacar cina & 0,03 & B80 & Keladi hijau & 0,13 \\
\hline B24 & - & 0,13 & B53 & pacar cina & 0,03 & B81 & Peach lily & 0,13 \\
\hline B25 & Dracaena s. & 0,16 & B54 & kuping gajah & 0,03 & B82 & Pakis Boston & 0,20 \\
\hline B26 & Puring & 0,03 & B55 & Kuping Gajah & 0,05 & & & \\
\hline B27 & Pucuk Merah & 0,16 & B56 & kosong & 0,00 & & & \\
\hline \multirow[t]{2}{*}{ B28 } & Pandan & 0,03 & B57 & kosong & 0,00 & & & \\
\hline & & & & & & & TOTAL & 6,60 \\
\hline
\end{tabular}

Tabel 5. Luas Total Tajuk Tanaman Rumah C \& D

\begin{tabular}{lllllllll}
\hline \multicolumn{1}{l}{ Jenis } & $\begin{array}{l}\text { Luas } \\
\text { Tajuk/m2 }\end{array}$ & & Jenis & $\begin{array}{l}\text { Luas } \\
\text { Tajuk/m2 }\end{array}$ & & Jenis & & $\begin{array}{l}\text { Luas } \\
\text { Tajuk/m2 }\end{array}$ \\
\hline C1 & Zamioculcas & 0,05 & D1 & Pakis Boston & 0,19 & D8 & Cemara embun & 0,16 \\
\hline C2 & Paku S. Burung & 0,07 & D2 & Cemara embun & 0,20 & D9 & Pakis Boston & 0,20 \\
\hline C3 & Paku S. Burung & 0,07 & D3 & Pakis Boston & 0,14 & D10 & Sirih gading & 0,06 \\
\hline & & & D4 & Pakis Boston & 0,34 & D11 & Zamioculcas & 0,36 \\
\hline & TOTAL C & $\mathbf{0 , 1 9}$ & D5 & Cemara embun & 0,26 & D12 & Zamioculcas & 0,33 \\
\hline & & D6 & Pakis Boston & 0,21 & D13 & Keladi & 0,24 \\
\hline & & D7 & Sirih gading & 0,11 & D14 & Sansevieria & 0,05 \\
\hline
\end{tabular}

Tabel 6. Luas Total Tajuk Tanaman Rumah E

\begin{tabular}{llllllllll}
\hline & Jenis Tanaman & $\begin{array}{l}\text { Luas } \\
\text { Tajuk/m2 }\end{array}$ & Jenis Tanaman & $\begin{array}{l}\text { Luas } \\
\text { Tajuk/m2 }\end{array}$ & & Jenis Tanaman & $\begin{array}{l}\text { Luas } \\
\text { Tajuk/m2 }\end{array}$ \\
\hline E1 & Episcia & 0,07 & E5 & Gel. Cinta & 0,01 & E9 & aglaonema & 0,01 \\
\hline E2 & Spider Lily & 0,01 & E6 & Kamboja jepang & 0,01 & E10 & keladi hijau & 0,01 \\
\hline E3 & Gelombang Cinta & 0,20 & $\mathbf{E 7}$ & peach lily & 0,01 & E11 & Jeruk & 0,13 \\
\hline E4 & Kamboja jepang & 0,01 & $\mathbf{E 8}$ & aglaonema & 0,01 & E12 & keladi hijau & 0,05 \\
\hline & & & & & & TOTAL E & $\mathbf{0 , 5 1}$ \\
\hline
\end{tabular}


Tabel 7. Luas Total Tajuk Tanaman Rumah G \& I

\begin{tabular}{lllllllll}
\hline Jenis & $\begin{array}{l}\text { Luas } \\
\text { Tajuk } \\
(\mathbf{m} 2)\end{array}$ & Jenis & $\begin{array}{l}\text { Luas Tajuk } \\
(\mathbf{m} 2)\end{array}$ & Jenis & $\begin{array}{l}\text { Luas Tajuk } \\
(\mathbf{m} 2)\end{array}$ \\
\hline G1 & Pakis Boston & 0,20 & $\mathbf{I 1}$ & - & 0,03 & $\mathbf{I 8}$ & Miana & 0,02 \\
\hline G2 & Pakis Boston & 0,16 & $\mathbf{I 2}$ & Miana Kuning & 0,03 & $\mathbf{I 9}$ & Miana & 0,02 \\
\hline G3 & Cemara embun & 0,07 & $\mathbf{I 3}$ & Hanjuang & 0,02 & $\mathbf{I 1 0}$ & Sirih Gading & 0,03 \\
\hline G4 & Pakis Boston & 0,20 & $\mathbf{I 4}$ & Miana Kuning & 0,02 & $\mathbf{I 1 1}$ & peperomia & 0,05 \\
\hline & 0,62 & $\mathbf{I 5}$ & Miana Ungu & 0,02 & $\mathbf{I 1 2}$ & Pakis Boston & 0,16 \\
\hline & & $\mathbf{I 6}$ & Miana Ungu & 0,02 & $\mathbf{I 1 3}$ & - & - \\
\hline
\end{tabular}

Tabel 8. Luas Total Tajuk Tanaman Rumah J\&K

\begin{tabular}{lllllllll}
\hline & Jenis & $\begin{array}{l}\text { Luas } \\
\text { Tajuk } \\
(\mathbf{m})\end{array}$ & & Jenis & $\begin{array}{l}\text { Luas Tajuk } \\
(\mathbf{m} 2)\end{array}$ & & Jenis & $\begin{array}{l}\text { Luas Tajuk } \\
(\mathbf{m} 2)\end{array}$ \\
\hline J1 & Anggrek & 0,02 & K1 & Dracaena & 0,03 & K10 & Keladi hijau & 0,07 \\
\hline J2 & Sirih Gading & 0,03 & K2 & Sirih Hijau & 0,02 & K11 & Episcia & 0,02 \\
\hline J3 & Pakis Boston & 0,10 & K3 & Miana & 0,02 & K12 & - & 0,02 \\
\hline J4 & Pakis Boston & 0,13 & K4 & Miana & 0,05 & K13 & - & 0,01 \\
\hline J5 & Sirih Gading & 0,03 & K5 & Keladi hijau & 0,05 & K14 & Keladi hijau & 0,05 \\
\hline J8 & Pakis Boston & 0,10 & K6 & Sirih Gading & 0,05 & K15 & Euphorbia & 0,05 \\
\hline J9 & Sirih Gading & 0,07 & K7 & Euphorbia & 0,05 & K16 & Anthurium & 0,10 \\
\hline J10 & Paku Tanduk R. & 0,03 & K8 & Anthurium & 0,07 & K17 & Dieffenbachia & 0,07 \\
\hline & & & K9 & Dieffenbachia & 0,03 & K18 & Anthurium & 0,05 \\
\hline & TOTAL J & $\mathbf{0 , 5 0}$ & & & & TOTAL K & $\mathbf{0 , 7 9}$ \\
\hline
\end{tabular}

Tabel 9. Luas Total Tajuk Tanaman Rumah L

\begin{tabular}{|c|c|c|c|c|c|c|c|c|}
\hline & Jenis & $\begin{array}{l}\text { Luas } \\
\text { Tajuk/m2 }\end{array}$ & & Jenis & $\begin{array}{l}\text { Luas } \\
\text { Tajuk/m2 }\end{array}$ & & Jenis & $\begin{array}{l}\text { Luas } \\
\text { Tajuk/m2 }\end{array}$ \\
\hline $\mathbf{L 1}$ & Proiphys a. & 0,28 & L18 & Dieffenbachia & 0,05 & L35 & Dieffenbachia & 0,07 \\
\hline L2 & peach lily & 0,20 & L19 & Dieffenbachia & 0,03 & L36 & Dieffenbachia & 0,01 \\
\hline $\mathbf{L 3}$ & Dieffenbachia & 0,13 & L20 & Dieffenbachia & 0,03 & L37 & Proiphys a. & 0,10 \\
\hline L4 & dracaena s. & 0,07 & L21 & Sansevieria & 0,07 & L38 & Dieffenbachia & 0,07 \\
\hline L5 & peach lily & 0,13 & L22 & begonia & 0,20 & L39 & Sansevieria & 0,03 \\
\hline L6 & Sansevieria & 0,10 & L23 & Episcia & 0,03 & L40 & Keladi hijau & 0,07 \\
\hline L7 & Sansevieria & 0,02 & L24 & Episcia & 0,02 & L41 & Sansevieria & 0,07 \\
\hline L8 & dracaena & 0,28 & L25 & dracaena s. & 0,20 & L42 & Pucuk Merah & 0,10 \\
\hline L9 & Proiphys a. & 0,20 & L26 & Keladi hijau & 0,02 & L43 & Pucuk Merah & 0,07 \\
\hline
\end{tabular}




\begin{tabular}{|c|c|c|c|c|c|c|c|c|}
\hline & Jenis & $\begin{array}{l}\text { Luas } \\
\text { Tajuk/m2 }\end{array}$ & & Jenis & $\begin{array}{l}\text { Luas } \\
\text { Tajuk/m2 }\end{array}$ & & Jenis & $\begin{array}{l}\text { Luas } \\
\text { Tajuk/m2 }\end{array}$ \\
\hline L10 & dracaena s. & 0,03 & $\mathbf{L} 27$ & Keladi hijau & 0,05 & L44 & Pucuk Merah & 0,03 \\
\hline L11 & dracaena & 0,13 & L28 & Dieffenbachia & 0,16 & L45 & Aglaonema & 0,13 \\
\hline L12 & dracaena & 0,07 & L29 & Keladi hijau & 0,02 & L46 & Aglaonema & 0,16 \\
\hline L13 & Dieffenbachia & 0,05 & L30 & Episcia & 0,02 & L47 & Pucuk Merah & 0,03 \\
\hline L14 & dracaena & 0,02 & L31 & Episcia & 0,03 & L48 & Spider Lily & 0,05 \\
\hline L15 & pacar cina & 0,03 & L32 & Episcia & 0,02 & L49 & walisongo & 0,07 \\
\hline L16 & Keladi hijau & 0,03 & L33 & Spider Lily & 0,07 & L50 & Spider Lily & 0,05 \\
\hline L17 & dracaena & 0,10 & L34 & Spider Lily & 0,02 & & & \\
\hline
\end{tabular}

Tabel 10. Luas Total Tajuk Tanaman Rumah M

\begin{tabular}{|c|c|c|c|c|c|c|c|c|}
\hline & Jenis & $\begin{array}{l}\text { Luas } \\
\text { Tajuk/m2 }\end{array}$ & & Jenis & $\begin{array}{l}\text { Luas } \\
\text { Tajuk/m2 }\end{array}$ & & Jenis & $\begin{array}{l}\text { Luas } \\
\text { Tajuk/m2 }\end{array}$ \\
\hline M1 & Spider plant & 0,04 & M22 & Episcia & 0,00 & M45 & anthurium & 0,15 \\
\hline M2 & Spider plant & 0,04 & M23 & dracaena s. & 0,05 & M46 & proiphys a. & 0,45 \\
\hline M3 & Spider plant & 0,04 & M24 & dracaena s. & 0,10 & M47 & anthurium & 0,11 \\
\hline M4 & Spider plant & 0,04 & M25 & keladi hijau & 0,02 & M47a & Spider plant & 0,08 \\
\hline M5 & Spider plant & 0,04 & M26 & keladi hijau & 0,13 & M48 & dieffenbachia & 0,08 \\
\hline M6 & Spider plant & 0,04 & M27 & anthurium & 0,26 & M48a & pandan & 0,08 \\
\hline M7 & Spider plant & 0,04 & M28 & proiphys a. & 0,24 & M49 & pakis boston & 0,20 \\
\hline M8 & Spider plant & 0,04 & M29 & anthurium & 0,11 & M50 & anthurium & 0,09 \\
\hline M9 & Spider plant & 0,04 & M30 & proiphys a & 0,23 & M51 & pakis boston & 0,28 \\
\hline M10 & keladi hijau & 0,07 & M31 & anthurium & 0,05 & M52 & spider plant & 0,05 \\
\hline M11 & balsam & 0,06 & M32 & anthurium & 0,04 & M53 & spider plant & 0,07 \\
\hline M12 & balsam & 0,03 & M33 & marantha bali & 0,17 & M54 & spider plant & 0,07 \\
\hline M13 & keladi hijau & 0,09 & M34 & anthurium & 0,14 & M55 & spider plant & 0,07 \\
\hline m13a & dieffenbachia & 0,05 & M35 & begonia & 0,07 & M56 & spider plant & 0,07 \\
\hline M14 & balsam & 0,03 & M36 & dieffenbachia & 0,07 & M57 & spider plant & 0,07 \\
\hline M15 & hanjuang & 0,27 & M37 & balsam & 0,03 & M58 & spider plant & 0,07 \\
\hline M16 & Monstera & 0,09 & M38 & anthurium & 0,15 & m58b & spider plant & 0,07 \\
\hline M17 & balsam & 0,04 & M39 & proiphys a. & 0,13 & M59 & bromeliad & 0,07 \\
\hline M18 & anthurium & 0,05 & M40 & dracaena s. & 0,17 & M60 & Spider plant & 0,03 \\
\hline M19 & dieffenbachia & 0,08 & M41 & anthurium & 0,14 & M61 & Spider plant & 0,09 \\
\hline M20 & dieffenbachia & 0,06 & M42 & euphorbia & 0,16 & M62 & pandan & 0,79 \\
\hline m20a & anthurium & 0,07 & M43 & balsam & 0,06 & & & \\
\hline \multirow[t]{2}{*}{ M21 } & Dracaena Janet & 0,31 & M44 & Agloenema & 0,25 & & & \\
\hline & & & & & & & TOTAL M & 7,42 \\
\hline
\end{tabular}


Tabel 11. Luas Total Tajuk Tanaman Rumah N \& O

\begin{tabular}{|c|c|c|c|c|c|c|c|c|}
\hline & Jenis & $\begin{array}{l}\text { Luas } \\
\text { Tajuk/m2 }\end{array}$ & & Jenis & $\begin{array}{l}\text { Luas } \\
\text { Tajuk/m2 }\end{array}$ & & Jenis & $\begin{array}{l}\text { Luas } \\
\text { Tajuk/m2 }\end{array}$ \\
\hline N1 & Keladi & 0,04 & 011 & walisongo & 0,15 & O29 & peperomia c. & 0,04 \\
\hline N2 & Sirih gading & 0,03 & 012 & Dieffenbachia & 0,11 & $\mathbf{O 3 0}$ & peperomia c. & 0,04 \\
\hline N3 & Episcia & 0,03 & 013 & walisongo & 0,20 & $\mathbf{O 3 1}$ & peperomia c. & 0,04 \\
\hline N4 & Sirih gading & 0,08 & 014 & Anthurium & 0,13 & $\mathbf{O 3 2}$ & peperomia c. & 0,04 \\
\hline N5 & Zamioculcas & 0,33 & 015 & kuping gajah & 0,09 & $\mathbf{O 3 3}$ & peperomia c. & 0,04 \\
\hline \multirow[t]{3}{*}{ N6 } & Zamioculcas & 0,07 & 016 & kuping gajah & 0,05 & 034 & peperomia c. & 0,04 \\
\hline & TOTAL N & $\mathbf{0 , 5 8}$ & 017 & kuping gajah & 0,05 & 035 & peperomia c. & 0,04 \\
\hline & & & 018 & kuping gajah & 0,07 & 036 & peperomia c. & 0,04 \\
\hline 01 & Walisongo & 0,10 & 019 & kuping gajah & 0,09 & 037 & peperomia c. & 0,04 \\
\hline O2 & Walisongo & 0,11 & O20 & kuping gajah & 0,04 & 038 & peperomia c. & 0,04 \\
\hline $\mathbf{O 3}$ & Anthurium & 0,09 & O21 & kuping gajah & 0,06 & O39 & peperomia c. & 0,04 \\
\hline O4 & Dracaena s. & 0,10 & O22 & pucuk merah & 0,16 & O40 & peperomia c. & 0,04 \\
\hline 05 & Anthurium & 0,15 & $\mathbf{O 2 3}$ & Bambu air & 0,05 & 041 & peperomia c. & 0,04 \\
\hline O6 & Hanjuang & 0,09 & O24 & kuping gajah & 0,13 & 042 & peperomia c. & 0,04 \\
\hline 07 & puring & 0,17 & 025 & Puring & 0,05 & 043 & peperomia c. & 0,04 \\
\hline 08 & Walisongo & 0,11 & 026 & walisongo & 0,13 & & & \\
\hline O9 & walisongo & 0,05 & O27 & kastuba & 0,24 & & & \\
\hline \multirow[t]{2}{*}{010} & walisongo & 0,26 & O28 & walisongo & 0,28 & & & \\
\hline & & & & & & & TOTAL O & 3,89 \\
\hline
\end{tabular}

Dari tabel perhitungan setiap rumah, dijumlah semua dan didapat total luas tajuk tanaman adalah sebagai berikut : $\mathrm{A}+\mathrm{B}+\mathrm{C}+\mathrm{D}+\mathrm{E}+\mathrm{F}+\mathrm{G}+\mathrm{H}+\mathrm{I}+\mathrm{J}+\mathrm{K}+\mathrm{L}+\mathrm{M}+\mathrm{N}+\mathrm{O}=$ $6,11+6,60+0,19+2,85+0,51+0+1,25+0+0,65+0,5+0,79+3,98+7,42+0,58+3,89=35,32 \mathrm{~m} 2$

\section{SIMPULAN}

1) Total jumlah tanaman yang berhasil diidentifikasi berjumlah 387 tanaman dengan total jenis 50 tanaman. Tiga tanaman yang paling banyak ditanam adalah sebagai berikut: 1) Spider plant 45 buah, 2) Pakis boston 34 buah dan 3) Keladi hijau 32 buah.

2) Cara peletakan tanaman yang berhasil dihitung dan diklasifikasi adalah sebagai berikut; 1)Tanaman diletakan dalam pot di atas tanah berjumlah 251, (2)Tanaman di tempel di dinding berjumlah 72 , 3)Tanaman digantung berjumlah 28, 4)Tanaman diletakan di pagar, dijepit, digantung atau ditempel berjumlah 22 5)Tanaman di tanam langsung di tanah berjumlah 14.

3) Luas tajuk tanaman adalah: A) $6,11 \mathrm{~m} 2$, B) 6,60 m2, C) $0,19 \mathrm{~m} 2$, D) 2,85 m2, E) $0,51 \mathrm{~m} 2$,F) $0 \mathrm{~m} 2$, G) $1,25 \mathrm{~m} 2$, H) $0 \mathrm{~m} 2$, I) $0,65 \mathrm{~m} 2$, J) 0,5 m2, K) 0,79 m2, L) 3,98 m2, M) 7,42 m2, N) 0,58 m2, O) $3,89 \mathrm{~m} 2$ dengan total $35,32 \mathrm{~m} 2$. 


\section{DAFTAR PUSTAKA}

[1] A. A. Saraswati, (2008). "Keberadaan ruang terbuka hijau dalam pembangunan kawasan industri," J. Tek. Lingkung., pp. 1-8.

[2] A. Riddati, (2014). "Study of the function of landscape plants on Laksda Adisucipto Street, Urip Sumoharjo Street, and Jendral Sudirman Street's greenway, Yogyakarta," Vegetalika, vol. 3, no. 1 , pp. 1-11.

[3] R. Nursyahbani, (2015). "KAJIAN KARAKTERISTIK KAWASAN PEMUKIMAN KUMUH DI KAMPUNG KOTA (Studi Kasus: Kampung Gandekan Semarang)," Tek. Perenc. Wil.

Kota, vol. 4, no. 2, pp. 267-281.

[4] KBBI, (1987). "Kamus Besar Bahasa Indonesia (KBBI)," https://kbbi.kemdikbud.go.id/, 2020.

[5] K. Heyne, Tumbuhan Berguna Indonesia, Jilid 1. Jakarta: Terjemahan: Badan Penelitian dan Pengembangan Kehutanan.

[6] U. Nurmayulis and N. Hermita, (2015). "Potensi Tumbuhan Obat Dalam Upaya Pemanfaatan Lahan Pekarangan Oleh Masyarakat Desa Cimenteng Kawasan Taman Nasional Ujung Kulon," Agrologia, vol. 4, no. 1, 2015, doi: 10.30598/a.v4i1.210.

[7] S. Purwanti, (2010)."Identifikasi dan Penilaian Visual Tanaman Hias di Kawasan Gembira Loka Yogyakarta Identification," vegetalika.

[8] Syamsia, (2017). "Pengembangan Lidah Mertua Sebagai “ Air Freshener ," no. December.

[9] A. Pratomo, S. Soedwiwahjono, and N. Miladan, (2019)."Kualitas Taman Kota Sebagai Ruang Publik Di Kota Surakarta Berdasarkan Persepsi Dan Preferensi Pengguna," Desa-Kota, vol. 1, no. 1, p. 84, doi: 10.20961/desa-kota.v1i1.12494.84-95.

[10] T. Ningtyas, (2019). "Pemanfaatan Ruang Terbuka Hijau (RTH) Publik Di Kota Kediri," $J$. Ilm. Manaj. Publik dan Kebijak. Sos., vol. 3, no. 1, p. 291, doi: 10.25139/jmnegara.v3i1.1898.

[11] O. Rodrigues, (2019). "Makna Ruang Terbuka Publik Taman Kota Largo De Lecidere Kota Dili, Timor Leste," Media Matrasain, vol. 16, no. 2, pp. 8-19. 